\title{
BMJ Open Experiencing the care of a family member with Crohn's disease: a qualitative study
}

\author{
Sofía García-Sanjuán, Manuel Lillo-Crespo, María José Cabañero-Martínez, \\ Miguel Richart-Martínez, Ángela Sanjuan-Quiles
}

To cite: García-Sanjuán S, Lillo-Crespo M, CabañeroMartínez MJ, et al. Experiencing the care of a family member with Crohn's disease: a qualitative study. BMJ Open 2019;9:e030625. doi:10.1136/ bmjopen-2019-030625

- Prepublication history for this paper is available online. To view these files, please visit the journal online (http://dx.doi.org/ 10.1136bmjopen-2019-030625)

Received 22 March 2019 Revised 25 September 2019 Accepted 27 September 2019

Check for updates

(C) Author(s) (or their employer(s)) 2019. Re-use permitted under CC BY-NC. No commercial re-use. See rights and permissions. Published by BMJ.

Faculty of Health Sciences, Department of Nursing, University of Alicante, Alicante, España

Correspondence to Dr María José Cabañero-

Martínez;

mariajose.cabanero@ua.es

\section{ABSTRACT}

Objectives To explore the experiences of caregivers living with relatives affected by Crohn's disease (CD) in a context in which the family provides social support.

Design A qualitative study based on a phenomenological approach was conducted through in-depth interviews.

Setting Participants living in Alicante (Spain) were recruited

Participants Eleven family caregivers of people with CD were interviewed.

Methods The in-depth interviews took place in the participants' homes and were audio recorded and then transcribed for a qualitative thematic analysis.

Results Five themes and accompanying subthemes were identified: (1) adaptation to the caring experience, (2) dichotomy 'with or without me', (3) unending burden, (4) need for knowledge and control of the disease, and (5) getting used to CD and normalising life.

Conclusion The findings contribute to an increase in the knowledge and comprehension of the experience of being the caregiver of a relative with $\mathrm{CD}$, which could be useful for professionals towards improving the quality of the CD caring process. Due to the temporal dimension of CD with frequent bouts of exacerbation and remission, family caregivers must adapt and acquire skills during chronic illness evolution. Moreover, the lack of family caregivers' inclusion and follow-up within the Spanish health system makes them feel invisible and useless, which may contribute to caregivers' burdens.

\section{INTRODUCTION}

Crohn's disease (CD) belongs to a group of chronic illnesses denominated as inflammatory bowel disease. It is characterised by bouts of exacerbation and remission, ${ }^{1}$ which reduce the quality of life of those affected..$^{23}$ Currently, anti-tumour necrosis factor treatments exist, ${ }^{4}$ which would appear to change the course of the disease, yet despite advances in medication in terms of symptomatology, healthcare services do not seem to be providing all the support people with CD require. ${ }^{5}$ This means a large part of the burden of attending to those affected falls on their family and within close circles. The latter group refers to a person who is the informal

\section{Strengths and limitations of this study}

- Our study results highlighted the life experience of family caregivers of people with Crohn's disease (CD) from a family-based culture.

- The study participants represented a range of different sociodemographic characteristics.

- Our results may contribute to improving the CD caring process in family contexts as well as the training of both health professionals and family caregivers regarding this topic.

- As all participants belonged to a Mediterranean culture, future research designs should focus on more diverse samples to explore other perspectives among different types of support of people with CD.

or family caregiver of a person with a non-invalidating chronicity, or chronic illness, with partial dependency. ${ }^{6}$

A family carer is defined as a person who provides long-term care to a sick person, often a family member or friend, and it does not include voluntary or remunerated formal carers. ${ }^{7}$ Although with this type of non-invalidating chronic disease, as is the case with $\mathrm{CD}$, the person developing the disease is not completely dependent on their carer, they do need someone to support them in facing the challenge of their health condition. ${ }^{8}$

People who suffer from CD require a dynamic family carer with certain characteristics, such as being able to identify their patient's needs and to provide support in decision-making or emotional support. ${ }^{9}$ This type of care implies a number of adjustments in their lives regarding family roles and changes in their lifestyles, such as reorganising schedules in order to fulfil personal duties, thus having a considerable impact on their quality of life. ${ }^{10}$

Often, family carers provide immediate care to people with chronic diseases. They are a family member who provides support and facilitates coping and the recovery of patients 
with chronic diseases. ${ }^{11}$ People affected by CD need a family carer prepared to assume the role of carer-supervisor, above all in contexts in which family support is important, ${ }^{12}$ whose aim is to maintain an optimum state of health of the person being cared for, according to the existing circumstances. Informal carers often divide treatment duties, ${ }^{13}$ sharing tasks that vary from practical to emotional support, decision-making or accompaniment to healthcare services, as well as compensating for the family roles of the sick family member and providing emotional support. All of these duties must be achieved by carers who are mostly self-taught and who lack logistical or emotional support. ${ }^{1415}$

Many studies have been conducted in relation to the perceptions and experiences of family carers of people with invalidating illnesses. However, studies about family carers living with people with non-invalidating chronic diseases are scarce. ${ }^{16}{ }^{17}$ In the case of $\mathrm{CD}$, several publications about carers' quality of life and their burden are available, although few have specifically focused on the carers' own experience. ${ }^{18} 19$

With the view of furthering the limited research performed to date on the experience of being the family carer of someone with $\mathrm{CD}$ and to address the wide range of concerns regarding how best to care for such people, the present qualitative study was undertaken in order to explore the experiences of informal carers within a context in which family represents social support. Therefore, the aim of this paper is to explore the experiences of carers of family members with CD.

\section{METHODS}

\section{Study design}

A qualitative study ${ }^{20}$ was performed in the province of Alicante on the Mediterranean Coast of Spain by using a contemporary phenomenological approach based on lifeworld research, which was described by Peter Ashworth ${ }^{21}$ and Karin Dahlberg as a blended approach that specifically explores how daily experiences manifest in the lifeworld of individuals through consideration of selfhood, sociality, embodiment, temporality and spatiality. Phenomenology is described as the study of phenomena as they manifest in our experience, of the way we perceive and understand phenomena and of the meaning phenomena have in our subjective experience. ${ }^{22}$ More simply stated, phenomenology is the study of an individual's lived experience in the world. ${ }^{23}$ By examining an experience as it is subjectively lived, such as the case of CD family caregivers, new meanings and appreciations can be developed to inform, or even reorient, how we understand that experience. However, in this study, phenomenology is used in terms of methodological application and guidance, which is the reason why an approach aligned with the study aim of exploring the life experiences of CD family caregivers was selected. Moreover, the in-depth interview was selected as an adequate technique for exploring the reality of participants from their own point of view. ${ }^{24}$ All interviews started with just one open question based on the study aim.

\section{Setting and participants}

The starting sample selection consisted of 19 family caregivers who were recruited through people with CD who participated in a previous study ${ }^{25}$ and were selected using the 'snowball' method, achieving what is known as maximum variation sampling. ${ }^{26}$ All participants were considered representative for the context of this study through the following inclusion criteria: being over 18 years old, not being a professional or paid carer and being the caregiver of a family member with $\mathrm{CD}$ diagnosed more than 5 years earlier. Most of the participants were women and had a direct relationship, either marital or consanguineous, specifically, the wife, sister or daughter of the participant with $\mathrm{CD}$, according to the typical Spanish caregiver's profile summarised previously by other authors ${ }^{27}$ : female and sole caregiver. The provision of chronic disease carers within a family in the Spanish culture does not occur equally among its members. It is usually the sole responsibility of one family member, most often a woman, who becomes the primary caregiver by performing numerous tasks and making complex decisions on a daily basis.

The principal investigator contacted the 19 participants via telephone calls, explaining the study characteristics and inviting them to participate. Afterwards, eight family caregivers rejected participation, and therefore,

\begin{tabular}{|c|c|}
\hline Characteristics & n (\%) \\
\hline \multicolumn{2}{|l|}{ Gender } \\
\hline Male & 2 \\
\hline Female & 9 \\
\hline \multicolumn{2}{|l|}{ Age (years) } \\
\hline $20-40$ & 3 \\
\hline $40-60$ & 5 \\
\hline $60+$ & 3 \\
\hline \multicolumn{2}{|l|}{ Relationship } \\
\hline Married/couple & 6 \\
\hline Sister & 1 \\
\hline Mother & 4 \\
\hline \multicolumn{2}{|l|}{ Education } \\
\hline Primary & 6 \\
\hline Secondary & 1 \\
\hline University & 4 \\
\hline \multicolumn{2}{|c|}{ Years since patient diagnosis } \\
\hline $0-10$ & 4 \\
\hline $10-20$ & 3 \\
\hline $20+$ & 3 \\
\hline
\end{tabular}


11 interviews were conducted with family caregivers of people diagnosed with CD (table 1).

\section{Ethical declaration}

This study was approved by the Ethics Committee of the University of Alicante (reference number: UA-2016-0620). All participants were informed by the researcher from the beginning about the study aim, the methods used and the type of interview that would be conducted if they accepted, including the information about the privacy and confidentiality of the data provided as well as their right to abandon the study at any time. Participants were also informed about the research team's purpose to share the study results with them once their study had ended. Prior to being interviewed, participants provided informed written consent, and acceptance was obtained from the institutions to which the personnel interviewed belonged. The informed consent documents for both the participant and the institution also included the objectives and main characteristics of the study.

\section{Data collection}

An appointment was planned with those who agreed to participate in the setting they freely chose. All of them selected their own home. The duration of the interviews was between 30 and $50 \mathrm{~min}$, neither counting the preambles and previous explanations nor the possible interruptions that could arise during them. The principal investigator was the interviewer, and each interview was audio recorded with the participants' permission. Prior to the commencement of the interviews, participants were informed of the voluntary and anonymous nature of the study and of their right to abandon whenever they preferred, and they were provided with an informed consent form containing a detailed description of the study characteristics, the rights and responsibilities relevant to their participation and the aims of the study in general. All in-depth interviews started with an open question asking broadly about the carer's experience. Data saturation was achieved at the ninth interview; however, the 11 planned interviews were conducted to collect as much data as possible, and the last two interviews left were of participants with different characteristics.

\section{Data analysis}

Data were analysed using content analysis based on phenomenology, according to Van Manen's ${ }^{28}$ recommendations and due to the approach selected. We explored both the expressed (consciously elaborated) and implicit factors that emerged in the interviews regarding the participants' experiences. Once the interviews were transcribed by the interviewer through software Express Scribe, the contents were presented to the participants for corroboration of the transcription accuracy. Following this, the thematic content analysis ${ }^{29}$ and subsequent production of results were performed.

The analysis was started individually by each researcher and was consequently categorised into themes with
Table 2 The themes and their constituent components or subthemes

\begin{tabular}{|c|c|}
\hline Themes & Subthemes \\
\hline $\begin{array}{l}\text { 1. Adaptation } \\
\text { to the caring } \\
\text { experience }\end{array}$ & $\begin{array}{l}\text { 1.1 Learning by discovery } \\
\text { 1.2 Feelings of frustration and guilt } \\
\text { 1.3 Tolerating the mood swings of the } \\
\text { affected person }\end{array}$ \\
\hline $\begin{array}{l}\text { 2. Dichotomy 'with } \\
\text { or without me' }\end{array}$ & $\begin{array}{l}\text { 2.1 Admiration for their resilience } \\
\text { against CD } \\
\text { 2.2 Feeling irreplaceable } \\
2.3 \text { Assuming the family role of the } \\
\text { affected person }\end{array}$ \\
\hline $\begin{array}{l}\text { 3. Unending } \\
\text { burden }\end{array}$ & $\begin{array}{l}\text { 3.1 Constant concern for their state of } \\
\text { being } \\
\text { 3.2 Uncertainties regarding the future } \\
\text { health of their family members } \\
\text { 3.3 Concerns regarding future family or } \\
\text { work issues }\end{array}$ \\
\hline $\begin{array}{l}\text { 4. Need for } \\
\text { knowledge and } \\
\text { control of the } \\
\text { disease }\end{array}$ & $\begin{array}{l}\text { 4.1 Constant search for information } \\
\text { 4.2 Perceived lack of information from } \\
\text { healthcare professionals }\end{array}$ \\
\hline $\begin{array}{l}\text { 5. Getting used to } \\
\text { and normalising life }\end{array}$ & $\begin{array}{l}\text { 5.1 Monitoring appointments and } \\
\text { paternalism } \\
5.2 \text { Solidarity with the affected person }\end{array}$ \\
\hline
\end{tabular}

$\mathrm{CD}$, Crohn's disease.

subthemes provided independently by each researcher. Once the transcriptions were checked by each member of the research team, the interviews were read and reread in their entirety by team members, who were all experienced in the topic and in qualitative analysis, aiming to formulate several ideas that could summarise the transcripts and to annotate any initially arising concepts. No digital analysis program was used. Once each researcher had identified the pertinent data individually, he or she created what he or she considered relevant themes and subthemes. At this point, a meeting was held in which each researcher presented his or her findings to the team. A discussion took place, and consensus was reached on coincident information, thus performing a triangulation process on the different sets of data. Through an iterative process of unitising, discussing the themes formulated individually and refining the agreed on themes and subthemes, the reliability gradually improved and finally reached a plateau of high reliability on average for the emergent themes and subthemes developed in consensus.

\section{Patient and public involvement}

No patient was involved in this study. We will thank patients both personally and publicly for their cooperation when reporting data in academic society.

\section{Findings}

Five themes with subthemes were identified from the resultant data analysed (table 2): (1) adaptation to the caring experience, (2) dichotomy 'with or without me', 
(3) unending burden, (4) need for knowledge and control of the disease, and (5) becoming accustomed and normalising life. We did not find differences among the caregivers' relationships; however, those with more years of experience and having lived through their relatives' surgical intervention provided more data compared with the rest, as was expected.

\section{Theme 1: adaptation to the caring experience}

\section{Subtheme 1.1: learning by discovery}

The people closest to those with CD stated they had had to learn by themselves to care for and attend their affected family members, as reported, 'It was very difficult, because we didn't know what to say, as there is no cure and we didn't know anything about the disease, but little by little we have learnt so far' (P06). They even had to learn mostly on their own regarding specific techniques: 'How to change the (colostomy) bag was explained to me in fivemin, and I was astonished, and at home, I learnt little by little, and in oneweek, I had it all under control by myself (P02).

\section{Subtheme 1.2: feelings of frustration and guilt}

Occasionally, participants expressed feeling unable to meet their family members' needs and provide them with the support they deserve: 'I think they should visit a psychologist, my help is not enough' (P05), and 'I tried to console her, but it was very difficult because, of course, there is no cure and sometimes, you don't know what to say or do' (P06). This feeling even appears when the caregivers believe they have not done enough to get the patients to a medical centre earlier: 'Well, you feel a little guilty, because you think, maybe if I had taken them at the start of the week instead of waiting...' (P07).

\section{Subtheme 1.3: tolerating the mood swings of the affected person} People who are in close circles of those diagnosed with CD complain that their family member has changed. According to them, the character of the person they care for changes, mostly when the disease is active and they have to live with the 'new' personality of the patient: 'He himself realizes that he is a different person, he's even lost his sense of humour, everything...' (P08), and 'And the way he speaks... he was rude to me, when he had never been like that' (P01).

\section{Theme 2: dichotomy 'with or without me'}

\section{Subtheme 2.1: admiration for their resilience against CD}

The interviewees often reported that they value the way in which their family members live with the disease: 'She happens to be a very positive woman and very keen to carry on, she always says she's fine, even though she's dying on the inside' (P09). They even feel admiration for their family members because, according to the carers, their sick family members are the ones who cheer up the surroundings: 'My wife is extremely strong, if I'm the one who is down, she is always cheering me up, without any psychological support' (P10).

\section{Subtheme 2.2: feeling irreplaceable}

Among the interviewees, there are constant manifestations in which they feel they are the only real support their sick relative has: 'Then the companion ends up a little tired, but if they aren't there, the patient sinks' (P11), and 'I'm the only one my sister could talk to, so besides being her sister, I am also her confidant, perhaps without me she would have needed a psychologist' (P03).

Subtheme 2.3: assuming the family role of the affected person When the health of a person with $\mathrm{CD}$ is diminished, either because they are having an active bout of the disease or because the consequences of the disease impede normal activity, the person at their side assumes the family roles that the former would otherwise occupy: 'When she is unwell, I take care of the child, so that she can rest and the child's life is not affected' (P07), and 'I acted as father and mother when my husband was hospitalized or was unwell (P02).

\section{Theme 3: unending burden}

\section{Subtheme 3.1: constant concern for their state of being}

The interviewees expressed feeling constantly alert regarding their family members' health since it is very important to them to know the state of being of the patient, and in most cases, patients conceal their true state of health: 'Since she always plays things down, you never know how she really is, and that worries me' (P07), and 'She doesn't tell me anything, until you go into the bathroom and see drops of blood in the toilet and then you ask her to tell you how she is' (P05).

\section{Subtheme 3.2: uncertainties regarding the future health of their family members}

Beyond being concerned for the true and current state of being of those affected by $\mathrm{CD}$, the people closest to them deal with concerns for the future health of their loved ones and the uncertainties of the future life they will face: 'It's always in the back of your mind that they might develop cancer or something like that' (P04), and 'And then you think they could have left the (colostomy) bag in place forever, or at some stage in their life they'll have to put another one in place and that is, well, it's complicated' (P02).

\section{Subtheme 3.3: concerns regarding future family or work issues}

When carers consider the future, they do not seem to give priority to their own future yet show a constant concern for their sick relative. This is reflected in their statements regarding sentimental relationships or keeping a job: 'They say they sacked him because his productivity had dropped, but I know otherwise, it's because he's sick, we'll see if he finds another job' (P01), and 'She was with a guy, but she didn't want him to see her scars, it was very hard for her and in the end they let it go, I don't know if she'll ever have a boyfriend again or if she'll remain single, and that worries me' (P09). They even consider whether or not their 'patients' will be able to have children and raise them: 'I feel as we are already helping them bring up a child, they couldn't have any more (children), because the illness stops them from having any extra energy' (P07), and 'Sometimes I ask whether she has thought about 
getting pregnant, but she always avoids the topic, I think it's something that worries her' (P11).

Theme 4: need for knowledge and control of the disease Subtheme 4.1: constant search for information

Despite those suffering from CD having extensive knowledge of their disease, their family members show a need to have the same or more knowledge than the person with the illness, either via the healthcare professionals they meet or web pages and social media:

Immediately I started searching the net and the Spanish Crohn's Association web page, and eventually, you find everything out and you're always connecting to web pages that are properly maintained and that you know are reliable. (P10)

The doctors do their rounds in the mornings, so I was none the wiser, until one afternoon I went to their room and asked them to explain everything to me about what was happening to him and what might come to pass, because it wasn't clear to me from what he was telling me. (P02)

They even create their own theories as to the appearance of the disease and its bouts: 'He developed it because he smoked a lot and because of the high levels of stress at work and due to the mortgage on the flat' (P01).

\section{Subtheme 4.2: perceived lack of information from healthcare professionals}

The family carers of people with $\mathrm{CD}$ feel that the information received from healthcare professionals is insufficient. In fact, most of their statements manifest not having sufficient information and having to look for alternative sources of information such as other people with $\mathrm{CD}$ or their family members:

The doctor told us it was a childhood illness, as if she had caused it herself, yet I left without knowing clearly what she had, and you end up speaking with different people... and what with how long she's had the disease, then you know what it is. (P09)

A proper explanation of how the disease acts and how it all works was never given. Likewise, when tests are to be done, no one explains what is involved or what different options there might be. You always have the feeling of a little lack of attention from the doctors. (P11)

Although, on the other hand, the possibility of placing their family member in the hands of a healthcare professional other than the reference doctor, despite never being completely satisfied with their work, finds them not wanting to change: 'Despite almost dying because they stopped the medication when they shouldn't have, we still see the same specialist' (P02).

\section{Theme 5: getting used to and normalising life}

Subtheme 5.1: monitoring appointments and paternalism

The interviewees accompany their family members to all of the medical appointments and keep track of the medication as if it were their own: 'I always accompany him to the doctor's appointments and, of course, to the tests, otherwise he loses track and doesn't know how to take his medication, so I keep track of it for him' (P08), and 'Either I go with her or my mother does, because her husband works, even if it's just a blood test. What's more, when she lived at home, I prepared her medication for her, because there were a lot of pills and she might have forgotten' (P07).

\section{Subtheme 5.2: solidarity with the affected person}

Living with people with $\mathrm{CD}$ would appear to limit the lives of family members, and this is expressed by the interviewees via restrictions they themselves have decided to impose on their own lives. Indeed, they prove to be devoted despite facing a situation involving chronic illness, and they accept the moments of solitude, in which they find themselves over the course of the illness, as normal:

You become accustomed to the disease. Yes, I could have used someone to help me, to be with me at times, because I was all alone, I felt very alone and people leave you alone... now I'm accustomed to the situation. (P04)

Before the strong bouts, I had always managed to accustom myself to it. I don't know, it's not like I saw it as something extremely severe, well, it does affect you, for example not being able to travel where you might like... but you get used to it and of course it does restrict you somewhat. (P10)

Well, since he's always tired, we don't go out at night, and as he can't eat numerous things, well, we can't go out for dinner either, so you just stay at home, and that's that. (P05)

\section{DISCUSSION}

The present study reveals the accounts of carers of family members with CD. Such care is complex and requires excellent competence and skills in order to meet the needs of their ill relatives and manage their own lives and those of their relatives. The findings of the present study reveal the conditions and challenges these family carers face by assuming their own family roles, as well as those of the person they look after and their particular healthcare needs.

At the time the family member is diagnosed, the person who is to become the carer is not familiarised with CD. The unawareness of the disease and how to deal with its progress, the physical and psychological needs of the person requiring care and the options and means of caring for them generated feelings of frustration among the participants of the present study, which in turn diminished their confidence and sense of control in order to serve as carers. ${ }^{30}$ As with other disease processes, ${ }^{31}$ the family carers in the present study assumed the provision of care with no knowledge or experience in dealing with the disease, the decision-making, the management of the 
complications and the interpersonal challenges yet to come, all of which could be facilitated if early-stage information was available regarding the progression of the disease, ${ }^{32}{ }^{33}$ information and support that would enable the carer and patient to plan for events that might arise in the future. ${ }^{34}$

Feelings of guilt and anxiety appear when family carers consider their behaviour is not aligned. ${ }^{35} \mathrm{~A}$ certain concern or burden is evident due to the constant apprehension about the present and future of their affected family member. Thus, in line with other studies, it can be seen that even when the disease is in remission, the carers experience stress. ${ }^{36}$

One explanation for the reason why they assume this role could be culturally based and related to a strong sense of obligation, maybe to avoid censorship from the rest of the family, because no one else can do it, or just for altruistic reasons. Similar to other studies, negative experiences are often described in terms of burden due to the constant demands that care entails, ${ }^{37}$ although a greater sense of warmth and satisfaction in their caring relationships was also highlighted. ${ }^{38}$

Although family carers face practical challenges, they must also deal with emotions and emotional outbursts from those affected with CD. Nonetheless, it would seem they are not proactively looking for help. Values, such as those that recent literature defines as 'familism',39 and moral obligation may explain such responses where carers might be reluctant to look for help since they perceive a strong sense of personal duty to care for sick or elderly family members. ${ }^{40}$ The 'cost' of informal care could be far reaching, resulting in widely recognised fatigue and diminished well-being. ${ }^{41} 42$

The results of the present study coincide with others in that family care involves positive sentiments such as love $^{43}$ and negative feelings such as constant concern. Prolonged and constant concern is exhausting. If carers have difficulty maintaining compassion, they may be at risk of developing harmful consequences, diminishing their quality of life and magnifying the burden of care. ${ }^{44}$ The findings herein indicate that the family carers participating in the present study needed considerable quantities of patience in order to maintain the necessary compassion to deal with the numerous frustrations associated with caregiving, as well as compassionate ways of dealing with frustration. ${ }^{45}$

Based on the premise that a family system consists of a small group of inter-related people and interdependent elements, ${ }^{46}$ in order to maintain the process and balance of family life, roles must be adjusted when the family system encounters challenges. ${ }^{47}$ This is exactly what occurs at each different stage of CD. The impact on any given family can be quite variable, for example, displays of anxiety and rage over the future of the caregiver's sick family member. The caregiver must make timely adaptations to adopt the caregiver role within the family system, especially during times of severe exacerbation of the illness. ${ }^{48}$
Given that an expert opinion contributes to a sense of calm and security, ${ }^{49}$ the carers interviewed stated they felt they had poor knowledge and understanding of the illness and its care requirements and therefore little confidence in the healthcare teams. A clear disconnection exists between patient needs and family carers and/ or healthcare providers. ${ }^{50}$ There is a large gap between the needs of family caregivers and the capacity of the current healthcare system to satisfy their needs. ${ }^{49}$

The chronic care paradigm must change from a patient-based scope to a patient-carer-based one in order to empower individuals and their families or support networks. ${ }^{51}{ }^{52}$ The importance of patient-centred care services has been emphasised in recent years by the most important health organisations such as the WHO and the European Commission, yet it is time to support the needs and preferences of carers as well. ${ }^{53}$ As with other chronic conditions such as cancer, taking into account the experience of the CD family caregivers would benefit the caregivers themselves. ${ }^{54}$

Those interviewed in the present study perceived a lack of resources, advice, information and emotional support from healthcare professionals. Merely knowing how to help would increase satisfaction and diminish concerns. ${ }^{45} 56$ Family members may appear to be invisible to the healthcare system, yet they are used as a resource and perform a wide range of tasks. ${ }^{57}$

Growing evidence suggests that family support for patients with $\mathrm{CD}$ greatly contributes to the management of such a condition. ${ }^{58}$ Healthcare services are increasingly considering that family carers of people with CD should collaborate with healthcare teams in order to achieve greater quality and effectiveness in the care process. ${ }^{59} 60$ Nonetheless, the results of the present study show that caregivers need the type of support that allows them to face challenges, take care of themselves and remain healthy in order to be able to support the burden of care. Health professional teams could include family caregivers of $\mathrm{CD}$ people in different interventions such as psychoeducational ones, psychotherapeutic ones, caring or even home-based supporting programmes. The effectiveness of applying those interventions with caregivers individually or by combining them according to the needs of the caregivers has been demonstrated. ${ }^{61-63}$

A tradition exists in Western culture based on potentiating isolated, autonomous and independent individuals, but the reality of a chronic illness, such as CD, and its management are undertaken as a social and family obligation in Mediterranean culture. In the present study's results, such ethical and moral implications can be observed in the actions performed for someone else's sake, namely the family member being cared for. Furthermore, confidence in others increases when the degree of attendance tends to increase. It can be said that family carers are directly involved in the lives of their sick relatives $^{6465}$ and as such, healthcare professionals must recognise the unique values and beliefs of their patients and their carers in regard to weighing treatments and other 
options and adjusting the healthcare services to their needs. ${ }^{66}$ There is a demand for improved healthcare education, information and quality of services for carers since carers must be recognised within the healthcare process. $^{67}$

\section{CONCLUSION}

The findings of the present study contribute to an increase in the knowledge and comprehension of the experience of being the family caregiver of a person with $\mathrm{CD}$. This caring process for chronic illness has a significant temporal dimension since $\mathrm{CD}$ is known for its bouts of exacerbation and remission, in which the carer must get adapted and acquire specific skills previously unknown for them as the disease keeps advancing. The lack of inclusion and follow-up of the caregiver within the Spanish health system makes them feel invisible and useless and may be related to the burden they reported.

Moreover, the lack of information and support for carers of people with $\mathrm{CD}$ would appear to go unnoticed by healthcare providers. Consequently, it is recommended that healthcare professionals and organisations incorporate $\mathrm{CD}$ carers' experience along with the caring process for $\mathrm{CD}$ people by implementing inclusive and culturally congruent programmes.

\section{Research limitations}

The results presented must be understood within the context of the limitations of this study. First, the present study is based on the information gathered in one sole interview, in which the carers were asked to describe their experiences up to that moment. The interviewees recruited were carers looking after family members diagnosed more than 5 years previously, yet a longitudinal study would be necessary to unravel the finer details inherent in the changes in the course of the disease. The data gathered reflect the experience of carers from the province of Alicante, Spain; thus, they cannot be extrapolated to other populations that do not possess similar characteristics. This geographical limitation should be addressed in future research with similar approaches in other provinces of Spain or similar cultures. A larger sample would allow a more complete understanding of the situation of family carers of people with CD. Nonetheless, this sample presented a variety of caregiving experiences at different stages of the disease and of different types of relationships, making the results presented transferable to other carers.

Acknowledgements The authors thank all the participants in this study.

Contributors All of the authors satisfy the necessary requirements to be recognised as such, including a substantial contribution to the manuscript and drafting it critically. SGS has made significant contributions to the idea and design of the study, to the data collection, and to the analysis and interpretation of data. She has worked on the drafting of the article and the critical review of its content. MLC has made significant contributions to the idea and design of the study, and to the analysis and interpretation of data. MJCM has participated in the analysis and interpretation of data. She has worked on the drafting of the article and the critical review of its content. MRM and ASQ have made significant contributions to the idea and design of the study, the critical review of its content, and obtained funding from the project.

Funding This study was funded by project 'Diseño de una vía clínica de patologías crónicas como la hipertensión arterial y la enfermedad de Crohn. Orientación a la gestión de procesos' (704753085-53085-45-514) integrated into the State plan I+D+I 2013-2016 Ministerio de Economía y Competittividad orientada a los Retos de la Sociedad and cofunded by ISCIII-Subdirección General de Evaluación y Fomento.

Competing interests None declared.

Patient consent for publication Not required.

Ethics approval Ethics Committee of the University of Alicante (reference number: UA-2016-06-20).

Provenance and peer review Not commissioned; externally peer reviewed. Data availability statement Data are available upon reasonable request.

Open access This is an open access article distributed in accordance with the Creative Commons Attribution Non Commercial (CC BY-NC 4.0) license, which permits others to distribute, remix, adapt, build upon this work non-commercially, and license their derivative works on different terms, provided the original work is properly cited, appropriate credit is given, any changes made indicated, and the use is non-commercial. See: http://creativecommons.org/licenses/by-nc/4.0/.

\section{REFERENCES}

1. Lichtenstein GR, Hanauer SB, Sandborn WJ. Management of Crohn's disease in adults. Am J Gastroenterol 2009;104:465-83.

2. Lynch T, Spence D. A qualitative study of youth living with Crohn disease. Gastroenterol Nurs 2008;31:224-30.

3. Moradkhani A, Beckman LJ, Tabibian JH. Health-Related quality of life in inflammatory bowel disease: psychosocial, clinical, socioeconomic, and demographic predictors. J Crohns Colitis 2013;7:467-73.

4. Maggiori L, Brouquet A, Zerbib P, et al. DOP037 Postoperative anti-TNF therapy is associated with a significant reduction of both endoscopic and clinical recurrence following surgery for ileocolonic Crohn's disease: results of a prospective nationwide cohort conducted by the GETAID chirurgie group. $J$ Crohns Colitis 2018;12:S056-7.

5. García-Sanjuán S, Lillo-Crespo M, Richart-Martínez M, et al. Healthcare professionals' views of the experiences of individuals living with Crohn's Disease in Spain. A qualitative study. PLoS One 2018;13:e0190980.

6. Saldaña DMA, Riaño HMC, Rubiano LAG. Quality of life of carers of patients with chronic diseases with partial dependence. Investigación en enfermería: Imagen y desarrollo, 2011: 13. 27-46.

7. Wright K. Cost-effecriveness in community care, 1987No. 033chedp.

8. Achury DM, Castaño Riaño HM, Gómez Rubiano LA, et al. Quality of life of carers of patients with chronic diseases with partial dependence. 13. Investigación en enfermería: Imagen y desarrollo, 2011(1).

9. de la Cuesta-Benjumea C. Building a world of care. Revista ROL de enfermería 2004;27:843-51.

10. Moreno SPC. Metasíntesis de calidad de vida en cuidadores familiares de personas en situación de enfermedad crónica. Tesis Doctoral: Universidad Nacional de Colombia, 2012.

11. Untas A, Rascle N, Idier L, et al. Family relations, mental health and adherence to nutritional guidelines in patients facing dialysis initiation. Psychol Health 2012;27:753-66.

12. García-Sanjuán S, Lillo-Crespo M, Sanjuán-Quiles Ángela, et al. Life Experiences of People Affected by Crohn's Disease and Their Support Networks. Clin Nurs Res 2016;25:79-99.

13. Kim Y, Schulz R. Family caregivers' strains: comparative analysis of cancer caregiving with dementia, diabetes, and frail elderly caregiving. J Aging Health 2008;20:483-503.

14. Díaz L. Cómo perciben Los cuidadores La situación crónica de enfermedad del niño. El arte Y La ciencia del cuidado. Bogotá: Unibiblos, 2002: 227-9.

15. Luna AGR, Garduño AG, Velázquez LET, et al. Changes in the daily life of the family due to chronic illnesses. Psicología y Salud 2013;20:111-7.

16. Oyegbile YO, Brysiewicz P. Family caregiver's experiences of providing care to patients with End-Stage renal disease in SouthWest Nigeria. J Clin Nurs 2017.

17. Pinto JMdeS, Nations MK. Cuidado E doença crônica: visão do cuidador familiar no Nordeste brasileiro. Ciênc. saúde coletiva 2012;17:521-30. 
18. Argyriou K, Kapsoritakis A, Tsakiridou E, et al. P154 quality of life (QOL) and inflammatory bowel disease (IBD): the caregiver's perspective. Journal of Crohn's and Colitis 2014;8:S126-7.

19. Zand A, Platt A, Van Deen W, et al. The Effect Of Inflammatory Bowel Disease On Patients' Caregivers. J Crohns Colitis 2016;10.

20. Guba E, Lincoln Y. Paradigmas en pugna en La investigación cualitativa. Handbook of Qualitative Research, Cap 1994;6:105-17.

21. Ashworth P. An approach to phenomenological psychology: the contingencies of the lifeworld. J Phenomenol Psychol 2003;34:145-56.

22. Smith DW. Phenomenology. Stanford encyclopedia of philosophy, 2013.

23. Van Manen M. Researching lived experience: human science for an action sensitive pedagogy. Routledge, 2016.

24. Giorgi A. Concerning the application of phenomenology to caring research. Scand J Caring Sci 2000;14:11-15.

25. García-Sanjuán S, Lillo-Crespo M, Richart-Martínez M, et al. Understanding life experiences of people affected by Crohn's disease in Spain. A phenomenological approach. Scand J Caring Sci 2017.

26. Patton MQ. Qualitative evaluation and research methods. SAGE Publications, inc, 1990.

27. Cuéllar Flores I, Sánchez López MP. Adaptación Psicológica en Personas Cuidadoras de Familiares Dependientes. Clínica y Salud 2012;23:141-52.10.5093/cl2012a9

28. Van Manen M. Educational research and lived experience: human science for a pedagogy of action and sensitivity. idea books, 2003.

29. Braun V, Clarke V. Using thematic analysis in psychology. Qual Res Psychol 2006;3:77-101.

30. Siu JY-man, Siu JY. Coping with patients suffering from overactive bladder: experiences of family caregivers in Hong Kong. Health Soc Care Community 2017;25:83-91.

31. de Vugt ME, Verhey FRJ. The impact of early dementia diagnosis and intervention on informal caregivers. Prog Neurobiol 2013;110:54-62.

32. Røthing M, Malterud K, Frich JC. Family caregivers' views on coordination of care in Huntington's disease: a qualitative study. Scand J Caring Sci 2015;29:803-9.

33. McCabe MP, Firth L, O'Connor E. A comparison of mood and quality of life among people with progressive neurological illnesses and their caregivers. J Clin Psychol Med Settings 2009;16:355-62.

34. Jowsey T, Strazdins L, Yen L. Worry and time: the unseen costs of informal care. Chronic Illn 2016;12:249-60.

35. Parveen S, Morrison V. Predicting caregiver gains: a longitudinal study. Br J Health Psychol 2012;17:711-23.

36. Zand A, Kim BD, Dvorsky M, et al. P748 high stress and significant decrease in productivity in caregivers of IBD patients. $J$ Crohns Colitis 2017;11:S464-5

37. Kang X, Li Z, Nolan MT. Informal caregivers' experiences of caring for patients with chronic heart failure: systematic review and metasynthesis of qualitative studies. $J$ Cardiovasc Nurs 2011;26:386-94.

38. Pressler SJ, Gradus-Pizlo I, Chubinski SD, et al. Family caregiver outcomes in heart failure. Am J Crit Care 2009;18:149-59.

39. Parveen S, Morrison V, Robinson CA. Ethnicity, familism and willingness to care: important influences on caregiver mood? Aging Ment Health 2013:17:115-24.

40. Bauer M, Fitzgerald L, Haesler E, et al. Hospital discharge planning for frail older people and their family. are we delivering best practice? A review of the evidence. J Clin Nurs 2009;18:2539-46.

41. Day JR, Anderson RA. Compassion fatigue: an application of the concept to informal caregivers of family members with dementia. Nurs Res Pract 2011;2011:1-10.

42. Öhman M, Söderberg S. The experiences of close relatives living with a person with serious chronic illness. Qual Health Res 2004;14:396-410.

43. Gusdal AK, Josefsson K, Thors Adolfsson E, et al. Registered Nurses' Perceptions about the Situation of Family Caregivers to Patients with Heart Failure - A Focus Group Interview Study. PLoS One 2016;11:e0160302.

44. Ågren S, Evangelista L, Strömberg A. Do partners of patients with chronic heart failure experience caregiver burden? Eur J Cardiovasc Nurs 2010;9:254-62.
45. Sullivan B-J, Marcuccilli L, Sloan R, et al. Competence, compassion, and care of the self: family caregiving needs and concerns in heart failure. J Cardiovasc Nurs 2016;31:209-14.

46. Doherty WJ. Family theory and family health research: understanding the family health and illness cycle. Can Fam Physician 1991;37:2423-8.

47. Wright LM, Leahey M. Nurses and families: a guide to family assessment and intervention. FA Davis, 2012.

48. Røthing M, Malterud K, Frich JC. Caregiver roles in families affected by Huntington's disease: a qualitative interview study. Scand $\mathrm{J}$ Caring Sci 2014;28:700-5.

49. Lee VYW, Seah WY, Kang AWC, et al. Managing multiple chronic conditions in Singapore - exploring the perspectives and experiences of family caregivers of patients with diabetes and end stage renal disease on haemodialysis. Psychol Health 2016;31:1220-36.

50. Ploeg J, Matthew-Maich N, Fraser K, et al. Managing multiple chronic conditions in the community: a Canadian qualitative study of the experiences of older adults, family caregivers and healthcare providers. BMC Geriatr 2017;17:40.

51. Olawale KO, Mosaku KS, Fatoye 'Femi Olusegun, et al. Caregiver burden in families of patients with depression attending Obafemi Awolowo university teaching hospitals complex lle-Ife Nigeria. Gen Hosp Psychiatry 2014;36:743-7.

52. Kouzoupis AB, Paparrigopoulos T, Soldatos M, et al. The family of the multiple sclerosis patient: a psychosocial perspective. Int Rev Psychiatry 2010;22:83-9.

53. Mirzaei M, Aspin C, Essue B, et al. A patient-centred approach to health service delivery: improving health outcomes for people with chronic illness. BMC Health Serv Res 2013;13:251

54. Ducharme FC, Lévesque LL, Lachance LM, et al. "Learning to Become a Family Caregiver" Efficacy of an Intervention Program for Caregivers Following Diagnosis of Dementia in a Relative. Gerontologist 2011:51:484-94.

55. Rangel-Domínguez NE, Ascencio-Huertas L, Ornelas-Mejorada $\mathrm{R}$, et al. Effects of problem solving on the self-care behaviours of caregivers of cancer patients in the palliative phase: a pilot study. Psicooncología 2013;10.

56. Røthing M, Malterud K, Frich JC. Balancing needs as a family caregiver in Huntington's disease: a qualitative interview study. Health Soc Care Community 2015;23:569-76.

57. Mora-López G, Ferré-Grau C, Montesó-Curto P. Analysis of the transition process among family caregivers in a hospital in the region of Catalonia in Spain. Appl Nurs Res 2016;29:242-7.

58. Coyne JC. Demonstration of a link between spouse depression and disability and disease activity of persons with rheumatoid arthritis. Arthritis Rheum 2009;61:1009-10.

59. Collins LG, Swartz K. Caregiver care. Am Fam Physician 2011;83

60. Lilly MB, Robinson CA, Holtzman S, et al. Can we move beyond burden and burnout to support the health and wellness of family caregivers to persons with dementia? Evidence from British Columbia, Canada. Health Soc Care Community 2012;20:103-12.

61. Nobili A, Riva E, Tettamanti M, et al. The effect of a structured intervention on caregivers of patients with dementia and problem behaviors: a randomized controlled pilot study. Alzheimer Dis Assoc Disord 2004:18:75-82.

62. Cameron JI, Shin JL, Williams D, et al. A brief problem-solving intervention for family caregivers to individuals with advanced cancer. J Psychosom Res 2004;57:137-43.

63. Slatyer S, Aoun SM, Hill KD, et al. Caregivers' experiences of a home support program after the hospital discharge of an older family member: a qualitative analysis. BMC Health Serv Res 2019;19:220.

64. Goldstein LJ. Collected Papers.Volume I: the problem of social reality, 1963.

65. Geertz C. Person, time and conduct in Bali. Yale University Southeast Asia Studies, 1966.

66. Pope C, Mays N. Critical reflections on the rise of qualitative research. BMJ 2009;339:b3425.

67. Sav A, McMillan SS, Kelly F, et al. The ideal healthcare: priorities of people with chronic conditions and their carers. BMC Health Serv Res 2015;15:551. 